\title{
Film and the Digital
}

\author{
By Rod Stoneman
}

Fall 2001 Issue of KINEMA

\section{RECYCLED ELECTRONS: FILM AND THE DIGITAL}

\section{I - Algebra in Cork}

To begin with a digression from digital history, which is a short history - the prehistory to the development of the digital world that we now inhabit is rarely in focus. It was a 19th century Irish mathematician, George Boole, who created a novel mathematical logic, describing a new algebra which sketched the structure of choice and created a paradigm for human, and now electronic, decision making. He wrote The Mathematical Analysis of Logic in 1847 and The Investigation of the Laws of Thought in 1854. He lived, thought and is buried in Cork.

His work showed chains of information and choice categorised into the two logic states of true or false: "Shall I go out and not stay in? Is it raining or has it stopped? If I go out and it's raining should I wear this rain coat and not that light jumper?" In 1937, nearly 75 years after Boole's death, a student at MIT recognised his theories as essential for the design of electronic circuits. Silicon semi-conductors that utilise transistor logic gates to change or maintain high / low voltage currents - digital signals.

The binary choice structure of Boolean algebra became the basis on which all computers everywhere are programmed. His trunk / branch / twig structure is the underlying framework that is reshaping our very mode of thought. It is Boolean algorithms that send search engines trawling through the further reaches of the internet.

\section{II - Shoot the money: Production}

Leaving their provenance aside, it is clear that the new machines are changing film-making and film viewing at enormous speed. The convergence of domestic and broadcast technology over the last two to three decades means that we are now at the stage where high quality images and sounds can be made on widely available equipment at modest cost. By the late eighties television engineers were already saying that Super VHS was almost equivalent to broadcast standard formats in terms of eventual image/sound quality, the difference being that a "professional" Betacam would continue to produce clear images in low light conditions which could not sustain "domestic" equipment.

New electronic moving image technologies have been in a complex and continuous process of development over the last thirty years - from the portapacks used in community video and in avant-garde practice since the early Seventies. There is no secret - the nexus of research and finance has continued to drive the development of the machines forward at a rapid rate.

In the Seventies the extension of access was understood as part of a wider change - the radical politicisation of cultural production initiated in 1968. For the first time the whole area of image/sound production was opened up on a significantly wider cultural and social basis. In artistic terms it provided access for the individual film-maker in his, or more rarely her, solipsistic self-expression. Now the auteurial film-makers' may be realised entirely in self-controlled digital images.

Significantly, the increased access to production also opened the possibility of community use - group action and self-representation. With the advent of video a "community of interest" could more easily record, argue and propagate its views; a reinforcement of self-identity and its transmission to a wider audience.

Shooting digitally has many new uses in the film and television industries, but it also challenges the permeable boundaries between the inside and the outside, undermining the old division between professional and nonprofessional. The origin of this separation can be traced to Medieval guild and apprenticeship structures. Like other culturally constructed categories: flower / weed, art / craft, it has always been open to question and challenge; but, there is a danger that they still operate invisibly, functioning to define and divide. They have a particularly powerful industrial function to exclude a whole range of people from access to production. 
The old British industry technician's adage to focus on the star "shoot the money" is part of a whole ideology insisting that "only (we) professionals know how to make film and television..."

There is also space for experimental visual play, arguably this is the crucial Research \& Development of the image economy. New digital forms have been adapted and adopted with alacrity by artists moving out of the gallery and college context into involvement in designing advertisements, title sequences and promos. This sector was quickly able to respond to multi-media with new forms of meaning and narrative. They exploited the specifics of Boolean structures to encourage the active participation of the viewer, making choices and moving through the interactive text in a novel, personal way.

In a culture which tends towards fixed meanings previously peripheralised experimental forms of meaning making are occasionally being shifted to more central positions and wider audiences. Artists' work in multimedia has the potential to a reposition new non-narrative forms of construction, deliberate ambiguity and polysemy, in that terrain. Mike Leggett, who curated Burning the Interface, an exhibition of international artists' work on CD ROM in Sydney, wrote "Convergence, as the term goes, is not only convergence of technologies but convergence of practices and disciplines. This is not just theoretical but actual when you look at the way the web is developing and the teams who produce the web phenomena quite apart from the extraordinary fringe / undernet activity which is really testing the credibility of "market-driven" sites...."

However, instead of looking for new ideas, new visions, new forms, many first time digital makers are compelled to replicate the mainstream. The vocational vortex pulls young film-makers towards an extremely normative commercial industry. More and more the indie picture resembles a low budget version of Hollywood fare. Apart from not playing fully to the specifics and potentials of the new equipment, it tries to compete with production values of images made on 1000 times the budget. The hegemony of Hollywood cannot be successfully contested on its own terrain.

Any hope for the new visual economy must lie in the development of dynamic new languages initiating a dialogue of new ideas... Dogme in Denmark has intervened dramatically with a deliberately mischievous manifesto to open a debate around films that arguably override the boundaries of documentary and fiction and push social taboos.

Their manifesto may be a moving target but it suggests that a body of work can be discussed in a specific framework. The group formulated an aesthetic embracing much larger shooting ratios and the immediacy of a high degree of improvisation in acting that implicitly arose from digital technology. The hand-held camera has played a role in the history of both vérité documentary and political fiction (Gino Pontecorvo and Peter Watkins) to signifying an immediate and powerful realism.

Although arguably one could imagine Visconti's or even Bergman's 35mm film version of Festen with the chandeliers in focus as part of the "Big House" genre in European cinema, clearly The Idiots or Dancer in the Dark could not conceivably have been made in any other way. Like Scratch video before it, Dogme is a premonition of new movements born of the imaginative appropriation of new technology.

\section{III - Soft and Hard: Post-production}

Opening out the means of shooting is also parallelled in terms of post-production: non-linear editing and digital effects. Although some European film-makers have been slow to grasp the implications of digital imaging, there is now more knowledge and usage for relevant sequences within features such as the apparition of the Madonna in Butcher Boy, or the virtuosic tracking shot through the four seasons in the Notting Hill market. This is a very piecemeal approach in comparison to the thoroughgoing embrace of digital manipulation for all aspects of a film in SFX movies like Mask, Matrix even Perfect Storm or Pearl Harbor. Sophisticated SFX on an epic scale are clearly not available to artiste / community film-makers, the exclusive economics of commercial potential tends to restrict access to the most expensive imaging equipment.

However, Nichola Bruce's I Could Read the Sky is an example of a modestly budgeted film with a richly layered image combination that could only have been built electronically. A long process of editing positioned each superimposed image's start and stop points, velocity and density (saturation). Jean Luc Godard's Soft and Hard and the seminal series Histoire du cinéma are previous examples of complex image sound manipulation worked through in his home / studio in Rolle, Switzerland. Significantly he called the company he formed with Anne-Marie Miéville Son Image. And as the complexity of non-linear editing available on laptop editors 
and home PCs continues to expand, the space for playful exploration of sound and music in relation to image will open up.

Leaving aside the entrance of new film-makers, this technology also provides opportunities for experienced film-makers to produce work more regularly, at a variety of budget levels. Derek Jarman's versatile alternation of larger budget 35mm production with his own artisanal Super 8 films was an early example of this. Joe Comerford's movement down budget, deliberately turning away from the Film on Four financed Reefer and the Model (1988) to the opportunity to work on a slower schedule with a smaller crew on High Boot Benny (1993) made for less than one third of the budget. The creative activity involved in film-making is like an enormous pyramid standing on its head, the tip representing the time during which film is running through a camera. The art involved in all stages of making a film strengthens and develops with work and experience. Jean Luc Godard compared the work of the film-maker to that of a taxi driver- "the cab driver gets on the road 300 days a year, I shoot for two months a year, if I'm lucky..."

The new cheaper availabilities of production and post-production are often taken together and presented as a much vaunted democratisation of the moving image. Certainly it is an entry point, providing opportunity and access to new talent which can be "spotted" and promoted via digital means.

But before we get carried away with our own idealism and optimism we should put this development in context. Cultural production always involves that ineffable, but important component - talent, brilliance, creativity. There has been a widespread cheap availability of the biro for a long time - but there are not a large number of great new novels published each year.

However it is clear that the gatekeeping process - spotting and selecting new talent - has now changed significantly. Aspirant film-makers can now find ways to realise their first films which don't involve knocking on the front door of institutional funding: colleges, national film agencies, television stations. All these generally involve complex processes of paper application. Now, liberated from the role of "homo applicans" and the necessity of institutional approval, film-makers can proceed to make the pictures and sounds themselves. The question is how to show them, how to reach an audience.

Huge amounts of under or un-financed new work is made under its own steam from the brave school of "go-for-it" outside of all funding structures. Festivals and distributors are now finding it hard to even view the vast quantities of unsolicited films being sent to them.

Whatever the format many television stations and film agencies have virtually fetishised the search for "new talent", encouraging scores of shorts and first features with a very few new directors going on to make even a second film. Clearly there are other cultural and social barriers which are factors in the filters of discovery. Digital formats will effect the structures of selection -whatever the attrition rate some strong new visions will find their way to new audiences.

\section{IV - Into the moronic inferno: Distribution}

Digital means of production connect with the development of new distribution sectors, although these will mostly be filled with previous forms of production. However as the new forms of distribution develop, there will be an inevitable persistence of vision reformatting itself as digital "content" - human drama, music, sport are still the most popular material to watch and therefore to sell. The desire for narrative means that, for most viewers, sexuality is subsumed within the genre "human drama" rather than the compressed terrain of pornography.

"Theatrical" public spaces will persist for exhibition but they cannot be constrained to any of the old forms of projection and techno-sectarianism! As long as the image resolution is good, the sound is well defined and powerful, the pleasures of "cinema" are experienced as easily via recycled electrons as the traditional form of silver halide crystals on celluloid.

Distribution and self-publishing via the internet is on the horizon. It was prefigured in the wonderful open library that Richard Brautigan imagined in his 1970 novel The Abortion, where anyone can write a book, register it and lodge it on the shelves. The profusion of many websites confirm that vanity publishing on the large scale rarely breaks out of its solipsistic origins. The digital future will enable makers to address a niche audience directly, but on a global basis. The possibility of connecting with niche markets internationally 
could transform the micro economy of isolated pockets of independent film production.

The Gutenberg Project was first initiated in 1971. As the result of the contribution of vast numbers of volunteers over a period of time, scanning and typing in a huge range of books and poems, it now offers a wide range of literary texts free on the internet. International literature is easily, immediately and freely available. There are mirror sites around the world and Walter Benjamin's essay "The Work of Art in the Age of Mechanical Reproduction" is enacted in the endless replication of digital information without loss of quality.

The extraordinary moment of Napster exemplifies the possibilities of reworking technology to exploit its potential for popular usage. It challenged the powerful financial interests by facilitating the replication of sellable goods. In a remarkably short space of time an international community began sharing - swopping and copying - music across the internet in a clear socialistic experiment. Defying record industry and copyright holders alike, 60,000 - 80,000 people could be found at any one time moving their music through Napster until the injunction set down by a District Court halted the process.

But the market struggles to reassert itself. The process of marketing always acts as a massive filtration, a powerful instrument in the process of selection. Even if everything is available it directs attention towards what is accessed and used. Roberto Benigni climbing on seats at an Oscar ceremony had a helpful effect on La vita è bella. "Holocaust lite", as it was apparently known in New York, became a significant commercial success, moving from modest local box office success to a world wide hit transforming the tenuous economy of arthouse cinemas in every part of the world. A relatively improvised random gesture, plus the very focused marketing skill and power of Miramax (capitalised by Disney) had an effect. More recently the magical combination of martial arts and Eastern mysticism in Crouching Tiger, Hidden Dragon has moved around the world by specific marketing and word of mouth. A significant achievement for a subtitled film.

Building brand recognition and loyalty to create selective choice in locating individual film titles becomes even more crucial in a multi-channel situation. The investment in achieving recognisable brands becomes vital in a crowded marketplace. However full blown international success in creating a brand, as with Microsoft, leads to market domination. In all the subsequent debates about distortion and lack of competition it is clear that the notion of the free market is not a neutral given but a constructed, created idea.

Transmission, streaming the moving image down the internet on demand will extend digital multi-channel television and offer domestic access to a 1000 channel universe. The delay in wider bandwidth provision necessary for streaming moving images has damaged digital expansion in the short term, but it is only a temporary delay. Continued digital proliferation on portable formats is likely as early discussion of JPEG 4 points towards the production of a CD disc with enough compression to contain 70-80 feature films. The much vaunted convergence may not take place exactly as foreseen however - there is an important distinction between the "lean-forward" screens for email or close interaction and the "lean-back" screens used for film and television viewing.

However the consumer's comfort of access will continue through the pre-selected front menu (Boolean trunkbranch-twig structures). Behind this other questions arise: What type of material? How is it chosen? What is the range of material easily available? Mostly commercial libraries recycling old content at low cost? How is the new material produced, at what cost per hour?

One of the most dramatic aspects of the new image economy is an apparent proliferation of choice. 50 cable channels all showing the same things - this the Situationists' "society of the spectacle" replicating itself. Saul Bellow, in a recent essay, referred to the speed and fragmentation of modern culture as the "moronic inferno".

To state the obvious, these developments take place in a context of significant social change and this technology is never neutral. Any aspect of a pro-active role is easily eroded - we are defined as passive receivers of a technology that has changed outside of human agency.

One could argue that the ubiquity of computers and their insertion into working and domestic environments could begin genuinely to close the gap between notions of producer and consumer and thus the reifications of industrial strata... Though the assumption some years ago of people developing teleworking / telecom- 
muting habits, for instance, seem to have been mostly rebutted, whereas the human battery farms of phonemarketing and call centres has increased exponentially - exactly opposing direction to self-determination and enfranchisement which has been so associated with the rhetoric of the "information age".

Are we in danger of becoming victims of our own hype? Of exaggerating the speed and the extent of change? The most likely scenario is one in which transformation will be uneven and diverse, continually modified by local conditions, local demands, expectations, resistances and compromises, the future still bearing the residual traces of the way it always was.

\section{V - Praemontius praemuntius}

Forewarned, forearmed. To what extent can film-makers move to create those local negotiations with a new global technological situation? Clearly some are decisively and unequivocally transforming the new opportunities provided by new technologies, which are not necessarily the opportunities envisaged by those that made them. There are extended openings for imagination, for intelligence, for direct speech and unmediated production. We must engage with the specific possibilities of cultural creativity that can play through the new technologies in the interstices of commercial prospects. We must look for the new ideas, new visions, new forms that can be organically integrated in the new visual economy, the development of a dynamic new language to create a dialogue of new ideas.

It is not just a question of pulling first time digital makers away from the vocational vortex which seeks to replicate the industrial mainstream in a lower budget mode. It is also a question of encouraging critical, independent work; for example the necessarily imaginative research (on paper and on screen), that engages with multi-media digital formats and non-linear narrative, that nurtures diversity and experiment.

Many film-makers are now embarking on micro-budget production using digital means. Perhaps development is a process which can now begin to take place in a camera and on a screen as well as through an endlessly photocopied draft script. It costs the same!

Film agencies and television companies must learn to enjoy the paradox of being institutions that recognise and respond to the extra-institutional. In many countries this will inevitably involve modernising union approaches and structures that are now anachronistic as they were formulated in relation to larger scale industrial budgets that are now less relevant to the evolution of indigenous cinemas.

There are always possibilities for inventive transformation and for the evasive action in relation to the constraints of the market. Those who sell the new machines propose formulaic uses for them. But an interception takes place as technology, determined from elsewhere, is decisively diverted and redirected. The electronic domain and its technological transactions offer many opportunities to deny and defy.

The terrain is changing all the time. "The philosophy of language involves rebuilding a ship at sea", as Ludwig Wittgenstein wrote (drafting Tractatus Logico-Philosophicus in Connemara in 1922). The flash of idealism is born of detachment. But then there can be a new engagement, this is needed to change the underlying relationships and avoid the old patterns or the new machines will just fall into old ways...

"From new transmitters came the old stupidities. Wisdom was passed on from mouth to mouth."(1)

\section{Notes}

1. Bertolt Brecht, "New Ages" in Poems: 1913-1956, New York: Methuen, 1976.)

\section{References}

This article is taken from a paper delivered an IBEC seminar held at the Great Southern Hotel, Galway on 9th July 1999, as part of the Film Fleadh. 


\section{Author Information}

Rod STONEMAN is Director to Huston School of Film and Digital Media, National University of Ireland in Galway. He previously served as Chief Executive of the Irish Film Board and a deputy commissioning editor of independent film and video at Channel Four. He has made several independent programmes for television (including "Between Object and Image," "Ireland: The Silent Voices," and "Italy: The Image Business"), written for Screen, Sight and Sound, Framework, and Afterimage. 